\title{
Measuring Hofstede's Five Cultural Dimensions at Individual Level and Its Application to Researchers in Tourists' Behaviors
}

\author{
Handayani Rinuastuti ${ }^{1}$, Djumilah Hadiwidjojo ${ }^{1}$, Fatchur Rohman ${ }^{1} \&$ Nur Khusniyah ${ }^{1}$ \\ ${ }^{1}$ Doctorate Program in Management Sciences Faculty of Economics and Business, Brawijaya University, \\ Malang, East Java, Indonesia \\ ${ }^{2}$ Management Department, Faculty of Economics and Business, Brawijaya University, Malang, East Java, \\ Indonesia \\ Correspondence: Handayani Rinuastuti, Doctoral Program in Management Sciences, Faculty of Economics and \\ Business, Brawijaya University, Malang, East Java, Indonesia. E-mail: hrinuastuti@yahoo.com
}

Received: October 16, 2014

Accepted: November 19, 2014

Online Published: November 25, 2014

doi:10.5539/ibr.v7n12p143

URL: http://dx.doi.org/10.5539/ibr.v7n12p143

\begin{abstract}
Depth understanding in the influence of national cultural background towards the tourists' behaviors and identifying the differences and similarities among the international tourism markets have nowadays become very fundamental compared to the past. Hofstede's cultural dimensions are perceived around the world as key indicators to differentiate within cultural groups, and this has been applied not only related to the values of works, but also common values and accepted as a universal cross-cultural. However, some criticisms towards Hofstede's cultural have too much leveled. This article aims to describe some of the reasons to the needs of cultural measurement at the individual level, especially its application in the study tourists' behaviors.
\end{abstract}

Keywords: Hofstede's cultural dimensions, individual level measurement, tourists' behaviors

\section{Introduction}

A theory by Hofstede (1980) on cultural differentiation has been widely used in many cross-cultural studies, especially in comparing various cultures between countries (Reisinger, 2009). According to the Social Science Citation Index, a total of 2,700 journal articles have referred to the writings by Hofstede (Yoo, Donthu \& Lenartowicz, 2011). Although Hofstede's Cultural Theory has been widely applied to a variety of marketing research, some cultural criticisms of Hofstede also widely expressed. Kirkman, BL, Lowe, KB \& Gibson, C. (2006) cited in Sivakumar and Nakata (2001) showed some of the weaknesses of Hofstede's Cultural Theory, namely: (1) Cultural conceptualized into four or five dimensions, so that the complexity of cultural context have becomes too simple; (2) Preparation of the basic cultural level is only performed on a single sample of multinational companies or multinational context; (3) The Hofstede's cultural values have failed to capture the cultural flexibility over time; and (4) The theory seems ignoring the cultural heterogeneity that may exist in the country.

Even though there are some disadvantages of referring to Hofstedes' cultural dimensions, according to Reisinger (2009) citing Mead (1998), these dimensions allow us as researchers to integrate as comparison within national cultures, which the comparison is beneficial worldwide as the key differentiator between cultural groups; it is acceptable to be applied not only related to the values of works, but also common values, as well as accepted as a cross-cultural universal (Reisinger, 2009).

The study by Hofstede (1980) has been replicated several times, and the results of the study were confirmed in different samples. In 2001, Hofstede's study was replicated on different international populations, the results obtained indicate that there are national and regional cultural groupings that may affect people's behaviors, but the behaviors tend to the values based on the five cultural dimensions of Hofstede (1980), and the dimensions have been stable over time.

Culture is the factor that has the most extensive influence on many dimensions of human behaviors. The extent of this effect may cause any difficulties to define the exact culture of human behaviors (McCort and Malhotra, 1993). These difficulties may hamper such researches concerning with the influence of culture on the human behaviors especially related to international consumption (McCort \& Malhotra, 1993; Dawar et al., 1996; 
Lenartowicz and Roth, 1999) and have been used to criticize cross-cultural research (Sekaran, 1983). Such a broad cultural influence on human behaviors encourages several experts to conduct research concerning with consumers' behaviors, especially with regard to culture as determinants of the consumers' behaviors. Similarly, this may also be applied to the tourists as consumers' behaviors in the tourism sector. Deep understanding of the influence of national cultural background of the tourists' behaviors and the identification of differences and similarities among the international tourist market has become very crucial concern compared to the past. Cultural differences may cause differences in terms attitudes among the travelers, opinions, emotions, and the tendency to make a purchase during their visit to any places (Reisinger, 2009).

Individuals from different cultures have different cultural values, rules of social behaviors, perceptions, and social interaction, which in turn the difference may affect the lifestyle, work patterns, how to relax and mingle or socialize with other people, and the patterns of their consumption behaviors (Richardson, 1988 in Meng, 2010). Cultural differences are often claimed as the basis of specific "stereotypes" given to the travelers who come from a certain nationality (Crotts \& Erdmann, 2000), so that it is assumed that what is shown or how tourists behave is based on their national culture.

Generalizing one cultural stereotype of one country directly with people of other countries could be fallacious (Yoo, Donthu, Lenartowicz, 2011; Irawanto, Ramsey \& Ryan, 2011). Culture in cross-cultural research has been defined at the national level. However, whether the individual in one state indicating cultural orientation which is consistent with the national culture still needs to be measured and clarified. Some researchers (Keillor et al., 2004; Kongsompong et al., 2009; Patterson et al., 2006; Patterson \& Mattila 2008 in Reid, 2011) argued that, marketers would gain greater level of success if they focus directly on consumers' characteristics and instead of focusing on the characteristics of the country. This conclusion is based on the argument that the individual values are as more accurate predictors of individual behavior (Lenartowicz \& Roth 2001). Thus, according to Prasongsukarn (2009) cultural orientation would be better related to the attitudes and behaviors of individuals or consumers. This article aims to describe the importance of conducting of the cultural reasons measurement at the individual level, especially its application in the study tourists' behaviors.

\section{Hofstede's Cultural Dimensions}

Hofstede (1991) has defined culture as the thoughts, feelings, and actions of human beings. According to him, culture is the human soul software (or might be software of the mind). The analogy stated by Hofstede is very interesting. He uses computer imagery to explain the role of culture in human life. The role of software is the determinant of the workings or operations of a computer; without the software, the computer becomes useless, in other words the one software which define the work of a computer. Hosftede wants to emphasize the importance of culture by proposing an analogy that culture is the software of the mind. Culture is a human drive, without it, human beings might be without meaning. Culture includes visible and invisible behavior that shape human behaviors.

Hostede's cultural framework is a model of the national culture which has been most widely referred to by several researches in psychology, sociology, marketing or even management (Sondergaard, 1994; Steenkamp, 2001; in Soares, 2007). Hofstede's cultural framework is the most comprehensive and reliable in terms of national culture samples (Smith et al., 1996; in Soares, 2007). Therefore the operationalization of cultural norms by Hofstede is commonly used in international marketing research (Dawar et al., 1996; Engel et al., 1995). The Hofstede's cultural dimension consists of: (1) power distance dimension, which reflects the extent to which groups of people who are weaker (have less power) in a culture to accept injustice and inequality in the distribution of power as a normal situation. Although injustice is commonplace situation found in all countries, but the level of public acceptance of the reality is different between cultures. According to Hofstede (1991) any state, group, or class society in particular, will be very easy to find the existence of inequality in some aspects which may give the color in life; (2) Individualism-collectivism dimension, which reflect the extent to which individuals in a culture in putting his own interests than the interests of the immediate family and other social groups, or the degree to which people in a country prefer to act as individuals rather than as members of a group. In a collective society, the identity and value of the individual are rooted in the social system than individual accomplishment or achievement. The reverse is found in people who tend to be individualists, who refer to the extent to which individual goals and needs to take primacy over the goals and the needs of the group; (3) Uncertainty avoidance dimension, which reflects the extent to which people in a culture feel threatened by uncertain situations where cannot be predicted or it is not clear, (4) Masculine-feminine dimensions. Masculinity is the dominant value of society that emphasizes rigor / assertiveness and earns money as well as other material goods. Femininity is the term used to refer to the extent to which the dominant values in society emphasize the relationship between human beings; and (5) Long-term orientation, which refers to the extent to which a culture 
has a pragmatic perspective of long-term or short-term historical orientation. Long-term oriented cultures tend to have values of prudence, resilience, perseverance, prioritizing efforts to build market share rather than pursuing short-term profits, respect for tradition, fulfilling social responsibility, and to preserve the honor of other people in the business.

Hofstede's cultural dimensions include the full and major conceptualizations of culture that have flourished for decades (Soares et al., 2007). Through a comprehensive review of the literature related to Soares et al. (2007), it is found any relevance of Hofstede's cultural dimensions on international business and consumer behavior. Similarly, in cross-cultural studies and social science many replicate as a typology of Hofstede and found it is the most important type of cultural theory (Chandy, Williams, 1994; Sondegaard, 1994, in Yoo et al., 2011).

\section{Tourists and Developing Tourism Sector}

Travelers or tourists are people who travel away from the normal day-to-day living. The trip was made at least overnight but not permanently and performed at the spare time out of daily work or do other routine tasks, but in order to find a memorable experience of interaction with some of the characteristics of selected places to visit (Goeldner \& Ritchie, 2011). The more extensive and open market in tourism, travelers resulted in the target market is also increasingly widespread. The disclosure provides an opportunity for tourists to visit the country in every aspect, with a background that is very much different from the country of origin or residence.

Tourists are visiting and entering such area with a background of life that has been shaping their behavior, and it becomes their characteristics. Even though they meet, they will interact not only with other tourists from other countries, but also with the local people with a much different atmosphere compared to the country of origin, behavior which has been formed a long time not just their release. Differences in languages, clothes, culinary, views, lifestyle, and various activities undertaken commonly were found among the tourists. Travelers from Japan, America, and Korea showed differences in their behavior during the tourist attractions (Pizam \& Jeong; 1996), differences in response and social interactions travelers Indonesia and Australia (Reisinger \& Turner, 1997), tourists Turkey, Europe, and Asia have also differences in decision-making in purchasing while traveling in Turkey (Nuray, Li \& Uysal, 2012), as well as behaviors of Japanese, Chinese, and Korean travelers show different tourism activities during their visit to Jeju Island Korea (Yu \& Ko, 2011).

As an individual who visits a new country or place, a tourist still has certain needs and desires that should be fulfilled. They need a break, need to eat, need sufficient information, and other needs according to their daily lives in the home countries. To meet various needs, they perform actions or activities that demonstrate their behavior to meet the needs for in the tourism places until they arrived back in their homeland.

Behavioral differences that occur cannot be avoided and will be found by the tourism actors in any tourism sectors. In short, understanding what and how the desire and willingness of the tourists as well as their behavior is an important factor for the success of tourism marketing activities. The international tourism trip continues to increase as predicted World Tourism Organization (WTO) in 2007, which has expected to reach 1.6 billion by 2020 (Reisinger, 2009). These conditions provide a very meaningful impact on the tourism industry. Foreign tourists from various countries with different backgrounds will dominate the international market, with diverse backgrounds and the behaviors are very diverse as well.

Travelers as consumers in the tourism industry have no significant different behaviors in principle with the behavior of consumers in general. In tourism, we are trying to understand why people travel, what they want to enjoy, and how they want to spend their money. From where tourists come from, from the environment where they come from, how they make decisions during their visit, and the elements that determine their travel decisions are fundamental factors that would be beneficial to determine the success of the tourism industry. Failure to understand the travelers and those associated with them is a serious error that could lead to negative consequences for the tourist as well as the industry as a whole, which in turn can lead to a decrease in demand for tourism visit or re-visit, the decline in sales and profitability, even lead to the failure of the tourism business (Reisinger, 2009).

Understanding how the behavior of travelers as well as various factors that may influence their behaviors is important thing that should be done by the various parties in the tourism activities. Pearce (2005); Reisinger (2009) stated that in order to improve the satisfaction, comfort of the tourists as tour players, increasing the positive contribution for the actors in the tourism industry, and the environment (the destination), understanding how tourists and behavioral factors that influence various things that need to be understood. Based on this information, management and the social and cultural environment will be able to enhance the experience of the tourists in a tourism area that will ultimately have an impact on the tourists, tourism stakeholders, and also the sustainability of the environment. 
Experience is terms of tourism context is a comprehensive understanding of tourists' behaviors, this might cover the participation and involvement of individuals in consumption and a state of physical, mental, emotional, social or spiritual, and which are largely shaped by individual consumers (Titz, 2007; O'Sullivan \& Spangler, 1998; Uriely 2005, in Walls \& Wang, 2011). Travelers will feel a good experience in the tourism area if it can meet their expectations and needs, both physically and emotionally (Walls \& Wang, 2011). Therefore, the physical elements such as facilities and infrastructure as well as their ease in activities, social interactions and relationships with fellow tourists, residents and workers in the field of tourism, as well as situational factors to be vital in providing a meaningful experience to the tourists.

In order to provide and create meaningful experience for the tourists in the tourism areas, how to create products attractions that can meet the desires and needs of the tourists, providing physical facilities that support a variety of activities and travelers' preferences in order to meet the physical and emotional needs of travelers into something that is very important note. According to Walls and Wang (2011), consumption experience meaningful and satisfying transaction may affect the values perceived consumption, satisfaction and encourage travelers to make decision to returned visits. In addition, understanding tourists' behaviors may provide sights for companies, non-profit organizations, and policy makers in marketing activities or determine its marketing strategy (Hawkins et al., 2004).

\section{Research in Cross-Cultural Tourists' Behaviors}

The increase of tourism trips may give implications for the diverse origins as well as cultural backgrounds of the tourists with different behaviors. Understanding tourists' behaviors in a cross-cultural context is very essential both in the perspective of the tourism industry, the tourists themselves, as well as the local residents (Reisinger, 2009). In developing tourism industry, understanding of the tourists' behaviors have increased the intense of researchers in cross-cultural field. Until now, researches in the field of cross-cultural have identified behavioral differences among travelers with different cultural backgrounds. Table 1 shows researches in the field of cross-cultural tourists' behavior.

Table 1. Researches in cross-cultural tourists' behaviors

\begin{tabular}{|c|c|c|c|}
\hline Researchers & Year & Objectives & Results \\
\hline Pizam-Sussman & 1995 & $\begin{array}{l}\text { Identifying tourists' behaviors from Japan, France, Italy, } \\
\text { America, during their visit in England. }\end{array}$ & $\begin{array}{l}18 \text { of } 20 \text { characteristics of the tourists' behaviors } \\
\text { of the four countries were different }\end{array}$ \\
\hline Pizam- Jeong & 1996 & $\begin{array}{l}\text { Identifying tourists' behaviors from Japan, America, and } \\
\text { Korea in Korea }\end{array}$ & $\begin{array}{l}18 \text { of } 20 \text { characteristics of the tourists' behaviors } \\
\text { of the three countries were different }\end{array}$ \\
\hline Reisinger-Turner & 1997 & $\begin{array}{l}\text { Identifying cultural differences between Indonesia and } \\
\text { Australia in the context of tourism }\end{array}$ & $\begin{array}{l}\text { There were } 30 \text { cultural differences between } \\
\text { Indonesia and Australia based on the tourist' } \\
\text { behaviors }\end{array}$ \\
\hline Reisinger-Turner & 1998 & $\begin{array}{l}\text { Investigating the importance of understanding cultural } \\
\text { differences between Australian travelers- workers in terms } \\
\text { of interactions, tourists' satisfactions, \& decision to } \\
\text { revisits }\end{array}$ & $\begin{array}{l}\text { There were tourists' behaviors of } \\
\text { Mandarin-speaking tourists and Australian } \\
\text { tourists }\end{array}$ \\
\hline Crotts-Erdmann & 2000 & $\begin{array}{l}\text { Investigating the influence of national culture (masculine } \\
\text { dimension) to consumers' evaluation to travel agents; } \\
\text { possibility for supporting repeated behaviors and positive } \\
\text { WOM }\end{array}$ & $\begin{array}{l}\text { There was limited indication that national culture } \\
\text { gave influence to consumers' evaluation to the } \\
\text { service by travel agent and their intention to recall } \\
\text { the agent or recommend to the other tourists }\end{array}$ \\
\hline M.Kozak & 2001 & $\begin{array}{l}\text { Identifying the level of satisfaction between tourists from } \\
\text { England and Germany in the same destinations }\end{array}$ & $\begin{array}{l}\text { Tourists from England had higher level of } \\
\text { satisfactions compared to tourists from Germany }\end{array}$ \\
\hline M.Kozak & 2002 & $\begin{array}{l}\text { Determining whether there are different motivations } \\
\text { between the same travelers to visit } 2 \text { different destinations, } \\
\text { and } 2 \text { different countries, same destinations }\end{array}$ & $\begin{array}{l}\text { There was difference in motivation of the tourists } \\
\text { based on their nationality and the places they } \\
\text { visited (push-pull motivations) }\end{array}$ \\
\hline Money-Crotts & 2003 & $\begin{array}{l}\text { Analysis of the relation between uncertainty avoidance } \\
\text { and information gathering, itinerary, traveling } \\
\text { characteristics (duration \& collective traveling) }\end{array}$ & $\begin{array}{l}\text { Tourists from countries with higher level of } \\
\text { uncertainty avoidance would gain more } \\
\text { information, buy tourism package, traveling with } \\
\text { big group, shorter duration, visit less destinations }\end{array}$ \\
\hline
\end{tabular}


Yuksel,Kilinc \& 2006 Exploring the differences and similarities of tourists' Yuksel behaviors from Turkey, Netherland, Great Britain, and Israel in complaining to hotel services
Woodside,Hsu, 2011 Applying comparative qualitative analysis (QCA/CGA) or Marshall

Selma,Li \& Uysa] 2012 consideration, preferences, and behaviors in understanding criteria of decision in tourism activities

Yun Yu, Gyou Ko 2012 Identifying cultural differences among tourists from China, Japan, Korea, and how those differences may influence on their perceptions and intense participations

Prayag \& Ryan 2012 Evaluating interactions between tourists and hotel staffs in determining tourists' satisfaction and dissatisfaction in Mauritius
There was moderate correlation between tourists' behaviors in terms of activities and complaining. There were some inconsistent scores between on Hofstede's cultural dimensions, \& the comparison among tourists from different countries showed that general assumptions towards Hofstede's framework might be debatable

There was direct influence from different culture to the tourists' behaviors. There was not enough proves in terms of correlation between age, first visit or revisit which enhance or hinder the culture-behavior of the tourists.

There was different criteria in determining decision by the tourists from different countries

There were significant differences on the tourists in perception and conducting activities in the destinations based on each country origin

Nationality, ethnicity, and language were the factors that differentiate tourists' satisfaction in interactions, where nationality became the most ample discriminant.

Table 1 shows the empirical evidence of differences in behaviors of the travelers who are from different cultural backgrounds. Some researchers use language difference as an indicator of cultural differences between tourists, but most of the cultural differences are indicated with different scores to Hofstede's dimensions, as indicators that show the differences in national culture or a particular nationality. This is in line with Reisinger (2009) that Hofstede's theory on cultural differentiation is very useful when analyzing the culture of one country.

The big differences in the behaviors of the tourists who come from different cultural backgrounds have been identified by most researchers across cultures and correlate the scores with Hofstede's cultural dimensions. The different results of the study were indicated by Yuksel et al. (2006) who related behavior complaints. Behavioral complaints among travelers Turkey, the Netherlands, UK, and Israel on hotel services showed considerable (moderate) relationship between attitudes and behaviors of the travelers in complaining something during their vacation. The results of this study also showed a number of inconsistencies between the scores of Hofstede's cultural dimensions and some comparisons between respondents from four different countries showed that the assumption that the general model of Hofstede's cultural dimensions might be debatable. The greater the power distances of a country, the greater the likelihood that the consumer of the country will be reluctant to take action against service failure. However, in contrast to the assumption that travelers Turkey, which has a high power distance (Hofstede, 1991), were found to have the same tendency to act like tourists from other states and the probability that they will voice their discontent is relatively higher than the tourists of cultural a smaller power distance (like the Netherlands). Consumers from individualist cultures are estimated to be more likely to complain to the hotel or third parties in the destination rather than individuals from collectivist culture who would be more likely to warn friends and relatives. The results obtained showed that the Turkish travelers with moderate collectivist cultures, when compared with individualist cultures (UK, the Netherlands and Israel), are also quite likely to perform behaviors that involve a third party. Although the difference was not significant, it was found that the Israeli tourists who have high individualism have a greater score tendency to warn friends and relatives rather than tourists from Turkey.

Most of the studies that have been conducted employed indirect inference value (benchmark approach). This approach refers to secondary data (Hofstede's national culture scores) to determine the characteristics of cultural groups without direct measurement of the members of the group. Lenartowicz and Roth (1999) suggest that this benchmark approach should be conducted very carefully: "The problem with this approach is the potential for error measurement that may occur due to extrapolation (generalization) of the cultural values of the group as measured by the benchmark to the sample studied." 


\section{Culture as the Cause, Not the Consequence}

The impact of 'Culture's Consequence' by Hofstede is indisputable (Steel, Taraz, 2010). As it has been proven from various reviews and references in cross-cultural studies (Kirkman et al., 2006; Ricks et al., 1990; Taras et al., 2010), as a culture as the cause has become the exclusive focus of cross-cultural researchers. Recent comprehensive review by Kirkman et al. (2006) and Tsui et al. (2007) reflected the general trend that sees culture as the cause and has never been considered as a result. In general, culture may be considered very stable, as stated by Hofstede (2001), national culture has not changed substantially "until at least 2100". Similarly, the general assumption that the cultural values of individual are formed in early childhood and remain unchanged throughout the life of someone; this is because by the time the children are reaching ten years old, most of the values are essentially may be programmed into the mind (Hofstede, 2001).

Some empirical evidences, however, show clearly that culture changes more frequently and more rapidly than it has been assumed previously (Adams, 2005 in Taraz, 2010). According to Steel and Taraz (2010) citing a theory in culture (Einstadt, 1973; Leung et al., 2005; Webber, 1968) stated that in a society that has been experiencing industrialization, modernization, and economic growth, they will be moving towards a set of values of industrialization; it is automatically, therefore, away from the traditional (conservative) values. The changes in cultural values show that culture is as result that can be influenced by various factors. Individual characteristics such as gender, age, generation, education level, and socioeconomic status and a country's characteristics such as GDP per capita, economic, political and civil freedom have been proven to be the influential factors to the changes of cultural values (Steel \& Taraz, 2010).

Someone who is at the top of the social hierarchy and organization are more often to engage in the decision-making process. As their everyday tasks which often go beyond the simple routines, they are more accustomed to uncertainty and ambiguity. In addition, the higher income of the individuals would provide economic security and independence/freedom to act. Therefore, the higher a person's employment status, this may increase the individualist orientation and masculine, and minimize power distance and uncertainty avoidance (Steel \& Taras, 2010). According to Steel and Taras (2010) citing Evans et al. (2000), when a person is mature enough, received more education, and grown up in the corporate level, the value of that person's culture is likely to change.

Heuer, Cummings, Hutabarat (1999) conducted a study related to the value of power distance on some managers in Indonesia and it was found changes in the orientation of the value hierarchy into a flat on the relationship among managers. Changes in society from an agrarian into industrialization brought impacts to the social change in the community (Henslin, 2006). As noted by Harbison and Myers (1964) in Heuer et al. (1999), industrialization has created more demands for people who are capable, as more and more people acquire more skills, equality emerged that may affect the status of the class. Elite become less distinguishable from the entire community, and the value systems become increasingly similar (Harbison \& Myers, 1964, in Heuer et al., 1999). Higher education, in addition, automatically will make someone may reach the middle class in the society (Hofstede, 1991). As a result of this industrialization process is the growing of middle class managerial group and this may create a context for cultural change (Hofstede, 1991).

The changes of country's characteristics such as the increase of political freedom of the country may increase individual and masculine orientation of the people, as well as lower power distance and uncertainty avoidance. According to Rai (2004) in Taras et al. (2010) who observed a change in the culture of Asian in which where obvious evidence in large cities people are experiencing economic growth. In the provinces, where the changes in the economic and socio-political change are much slower, cultural change tends not to occur. These findings support the idea that culture can be changed in response to changes in economic, political, and social systems. In contrast, there was no possibility of cultural change that occurred in the community with a stable economic and political environment (Evans et al., 2000). The results of the analysis (Taraz et al., 2010) have several implications for future researches, namely:

1) Supporting the idea that culture can be changed in response to the changes in economic, political, and social systems. In contrast, there was no possibility of cultural changes that may occur in a community with a stable economic and political environment. Therefore, the national index and ranking of the previous studies (Hofstede, 1980) may be invalid as the accuracy decreases when country characteristics have been changing over time.

2) The need or analysis with close attention should be given to the individual level. At the group level, entities such as professional societies, socio-economic class, the average age of group, and the group generation become more meaningful in terms of their ability to grow in a cluster of individual cultures, although 
geography remain a valid predictor of the value of culture for some time, a much more reliable variance if we include the individual level during analysis.

\section{Measuring Culture and Ecological Fallacy}

Culture can be defined and studied at different levels and has been often debated among experts, especially in terms of the level of analysis related to the concept of culture is worthy of being a tool (Hofstede 1991; Laroche 2007; Sharma, 2009; Steenkamp, 2001; in Reid, 2011). One of the reasons is the shared nature of culture, implying that culture is not necessarily directly connected to the individual, but at the same time there are also difficulties to establish how many people should share 'culture' within a cultural group (Dahl 2004, in Reid, 2011). Individual cultural value system covers elements of cultural values of the individual with those in the group and the unique values belonging to the individual (Triandis, 2001). This means that, on one point individual 'define' culture, on the other hand the individual is determined by the culture in their social group; the individual is conditioned by the socio-cultural environment in conducting activities in a certain way (de Mooij, 2004; Triandis, 2001).

The picture shows that the culture has been operationalized at various levels, and the presence of several layers of 'cultural programming' covers a wide range of operational culture of the individual behaviors (Hofstede, 1991). Progress in understanding the influence of culture may be hampered if the cross-cultural marketing researches simply generalize culture over one single (unanimous) country's culture (Lenartowicz \& Roth, 1999). The terms culture, state, nation, and people have often been used interchangeably (Dahl, 2004; Nakata and Huang, 2004; Schaffer \& Riordan, 2003, in Reid, 2011; Sekaran, 1983; Taras et al., 2010). Reid (2011) citing Steenkamp (2001) found that there was not empirical support for the differences within and between countries that makes nationality is accepted as a cultural proxy. Similarly, Hofstede (1991) argues that countries "are the source of a large number of common mental programming for their citizens" because the countries with a long history have become a driving force towards further integration. However, this does not mean that the same country and culture on national boundaries do not always coincide with a culturally homogeneous society (Gallivan \& srite, 2005; Karahanna et al., 2006 in Reid, 2011), which means that the operationalization of culture with this pragmatic way may reduce the richness of cultural concepts (Cleveland \& Laroche, 2007; Laroche, 2007; Zhang et al., 2008 in Reid, 2011).

Based on these reasons, some researchers have become more vocal about their view that marketers are more likely to succeed if they are directing attention to the characteristics of consumers instead of focusing on the characteristics of the country (Keillor et al., 2004; Kongsompong et al., 2009; Patterson et al., 2006; Mattila \& Patterson, 2008a, in Reid, 2011). This conclusion is based on the argument that the individual values are more appropriate and valid predictors on individual behaviors (Lenartowicz \& Roth, 2001). From the same perspective Dake (1991, in Reid, 2011) proposes that culture should be measured from the "individual orientation towards what we think of as culture, because culture is internalized by people, becoming part of the personality and affecting the people in doing transactions with the social and physical environment."

The following are some arguments which have been referred as the justifications to support measuring culture at the individual level (Reid, 2011):

1) Some researchers argue that the conventional method of using the state or country as a cultural unit of analysis or as the basis for market segmentation may be less appropriate to be used as the countries where the fact the global development led to such multicultural community (Cleveland \& Laroche, 2007; Laroche 2007; Tse et al., 1988). Craig and Douglas (2006) state that "deterritorialization, market fragmentation, and the development of relationships cross national borders may imply that one national culture is no longer relevant exclusively as the unit of analysis to examine the culture," which means that the researcher does not have to be too dependent on the state or country as one single unit of analysis. In countries that are relatively homogeneous, individuals vary in the extent to which they identify, adhere to, and practice of cultural norms (Gallivan \& Srite, 2005; Karahanna et al., 2006), there might be possibility of an individual from one culture shows characteristics more similar 'norm' of other cultures (Donthu \& Yoo, 1998). This may cause into the difficulty to define the boundaries of a particular culture.

2) From the methodological perspective, Yoo and Donthu (2002) and Sharma (2009) argue that the use of national generalizations to explain the behaviors of individuals or travelers is an ecological fallacy because state-level relations and characteristics are interpreted as if they were applied to the individual. Meanwhile, on the other hand Hofstede et al. (2010) argues that the model only applies to the national level of analysis and may not be suitable for studying the cultural orientation of individuals.

Applying Hofstede's cultural typology at the individual level is a reasonable because the values of an individual are identified in terms of the selected cultural dimensions (Donthu \& Yoo, 1998). Thus, research which employs 
cultural dimensions of citizenship will not provide greater explanatory power, as this will enable researchers to find differences in the attributes and characteristics, cultural norms, so as to draw conclusions beyond the countries involved in their research sample (Keillor et al., 2004; Lenartowicz \& Roth, 1999; Matsumoto \& Yoo Hee, 2006; Patterson et al., 2006 in Reid, 2011). For this reason, researchers in consumers' behaviors should emphasize the importance of measuring the cultural values at the individual level (Matsumoto \& Hee Yoo, 2006; Patterson et al., 2006, in Reid, 2011; Prasongsukarn, 2009; Soares et al., 2007; Yoo \& Donthu, 2011).

However, unlike in certain consumer research conducted in which the size of the individual to accurately measure one difference from the other, the size of Hofstede's research has been used at both the individual and is used to index the national culture according to their national identity. For example, Yoo et al., (2011) citing Aaker and Lee (2001) described China as a collectivist and all Americans as individualists. Dawar and Parker (1996) grouped participants based their research on national identity and determined Hofstede's national index to them in order to examine the effects of culture on the consumers' behaviors. This tradition is more acceptable when the unit of analysis is the country (or culture is used as a contextual variable), but not exactly when this study examined the effects of individual cultural orientation. Measuring individual and cultural orientation does not equate with the national culture; this may prevent researchers from errors that may occur when the ecological or state relationships are interpreted as the culture at individual level. Using Hofstede's size as a contextual variable has become a tradition. This is a distinct advantage and will continue to be a mainstream scale to use. However, to get an alternative need to assess Hofstede's cultural dimensions at the individual level, for example for countries with heterogeneous populations or for the cultural level of the individual in determining segmentation.

\section{Conclusion}

Culture has a strong influence on consumers' behaviors (Schiffman \& Kanuk, 2007) and the fundamental determinant of a person's desires and behavior (Kotler, 2003). Psychologically, the environment (including culture) is very influential in shaping someone's personality (Skinner, in Anwar, 2010). Similarly, in a study of cross-cultural tourists' behaviors, in line with the development of tourism, understanding cultural background and tourists' behaviors becomes more important.

Hofstede's framework is a shortcut which is simple, practical, and also beneficial to integrate culture into the study. However, cross-cultural tourists' behaviors studies often employed indirect values inference approach (benchmark), and potentially cause invalid measurement that may occur due to extrapolation (generalization) the cultural values of the group as measured by the benchmark to the sample studied. Changes in cultural value orientations as a result of industrialization, modernization, and economic growth, indicate that the culture is a result that can be influenced by various surrounding factors. In addition, the state as a cultural unit of analysis or as the basis for market segmentation may be less reliable to be used as the countries in the world have led to the multicultural, and this may cause difficulty to define the boundaries of a particular culture. The use of national generalizations to explain the behavior of individuals is an ecological fallacy because state-level relations are interpreted as if they were applied to the individual. Therefore, measuring the Hofstede's cultural dimensions at the individual level will provide an important contribution to cross-cultural research in the future and provide a higher level of success for the tourism industry in marketing activities.

\section{References}

Azwar, S. (2010). Sikap Manusia, Teori dan Pengukurannya (2nd ed.). Pustaka pelajar.

Cort, M. D., \& Maholtra, N. K. (1993). Culture and Consumer Behavior: Toward an Understanding of Cross-Cultural Consumer Behavior in International Marketing. Journal International Consumer Marketing, 6(2), 91-127. http://dx.doi.org/10.1300/J046v06n02_07

Crotts, H. (2004). Cross Cultural Tourist Behavior: A Replication and Extension Involving Hofstede's Uncertainty Avoidance Dimention. International Journal of Tourism Research.

Crotts, J., \&Erdmann, R. (2000). Does National Culture influence Consumers' Evaluation of Travel Services? A test of Hofstede's Model of Cross-cultural Differences. Managing Service Quality, 10(6), 410-419. http://dx.doi.org/10.1108/09604520010351167

Dawar, N., Parker, P., \& Price, L. (1996). A Cross-cultural Study of International Information Exchange. Journal International Business Study, 27(3). http://dx.doi.org/10.1057/palgrave.jibs.8490142

De Mooij, \& Marieke, K. (2004). Consumer Behaviour and Culture: Consequences for Global Marketing and Advertising. London: Sage. 
Eres, M. G. (2004). A Dynamic, Multilevel Model of Culture: from the Micro Level of Individual to the Macro Level of a Global Culture. Apllied Psychology: An International Review, 53(4).

Evans, G., Hutton, C., \& Kuoh, K. E. (2000). Where China meets Shouteast Asia: Social Culture Change in Border Regions. Institute of Southeast Asia Studies, Singapore.

Goeldner, R. (2011). Tourism Principles, Practice, Philosophies (12th ed.). John Wiley \& Sons. Inc.

Hawkins, B. C. (2004). Consumer Behavior, Building marketing Strategy. International Edition, Mc-Graw Hill Companies, Inc.

Heuer, M. C., Jeffry, L., \& Hutabarat, W. (1999). Cultural Stability or Change among Managers In Indonesia? Journal of International Business Studies, 30, 599-610. http://dx.doi.org/10.1057/palgrave.jibs.8490085

Hofstede. (2010). Dimensionalizing Cultures: The Hofstede Model in Context. Online Reading in Psychology and Culture, Unit 2. Retrieved from http://scholarworks.gvsu.edu/orpc/vol2/iss1/8

Hoftstede. (1991). Cultures and Organizations, Software of the Mind. New York: McGraw-Hill.

Irawanto, D. W., Ramsey, P. L., \& Ryan, J. C. (2011). Tailoring leadership theory to Indonesian culture. Global Business Review, 12(3), 355-366.

Ji-Yun, Y., \& Gyou, K. T. (2012). A cross-cultural study of perceptions of medical tourism among Chinese, Japanese and Korean tourists in Korea. Journal Tourism Management, 33(2012), 80-88. http://dx.doi.org/10.1016/j.tourman.2011.02.002

Kirkman, B. L., Lowe, K. B., \& Gibson, C. (2006). A quarter century of Culture's Consequences: A review of the empirical research incorporating Hofstede's cultural value framework. Journal of International Business Studies, 36(3), 285-320. http://dx.doi.org/10.1057/palgrave.jibs.8400202

Kongsompong, G. P. (2009). Cllectivism and Social Influence in the Buying Decision: A Four Country Study on Inter and Intra-National Differencess. Australasian Marketing Journal. http://dx.doi.org/10.1016/j.ausmj.2009.05.013

Kotler, P. (2003). Marketing Management (11th ed.). International Edition, Prentice Hall.

Kozak, M. (2001). Comparative Assessment of Tourist Satisfaction with Destinations Across Two Nationalities. Journal Tourism Management, 391-401. http://dx.doi.org/10.1016/S0261-5177(00)00064-9

Manrai, L., \& Manrai, A. (1996). Current Issues in the Cross-Cultural and Cross-National Consumer Research. Journal International Consumer Marketing, 8(3/4), 9-22. http://dx.doi.org/10.1300/J046v08n03_02

Meng, F. (2010). Individualism/ Coolectivism and Group travel Behavior: a Cross- cultural Perspective. International Journal of Culture, Tourism, and Hospitality Research. http://dx.doi.org/10.1108/17506181011081514

Money, C. (2003). The Effect of Uncertainty Avoidance on Information Search, Planning, and Purchases of International Travel Vacations. Journal Tourism Management. http://dx.doi.org/10.1016/S0261-5177(02)00057-2

Nuray, L. U. (2012). Cross Cultural Differences in Purchase Decision Marketing Criteria. International Journal of Culture, Tourism and Hospitality Research.

Pearce, L. P. (2005). Tourist Behavior; Themes and Conceptual Schemes. Cromwell Press.

Pizam, S. (1995). Does Nationality Affect Tourist Behavior? Annals of Tourism Research, 22(4), 901-917. http://dx.doi.org/10.1016/0160-7383(95)00023-5

Pizam-Abraham, \& Gang-Hoan, J. (1996). Cross-Cultural Tourist Behavior; Perception of Korean Tour-Guides. Journal Tourism Management, 17(4), 277-289. http://dx.doi.org/10.1016/0261-5177(96)00019-2

Prasongsukarn. (2009). Validating the Cultural Value scale (CVSCALE) a Case Study of Thailand. ABAC Journal, 29(2), 1-13.

Prayag, R. (2012). Visitor Interactions with Hotel Employees: The Role of Nationality. International Journal of Culture, Tourism and Hospitality Research.

Reid, V. (2011). A Study of the Influence of Individual Level Culture Value Orientation on the Formation of Service Quality Expextations. Disertation for the degree of Doctor of Philosopy, University of Nottingham.

Reisinger, T. (1998). Cultural Differences between Mandarin - Speaking Tourists and Australian Hosts and Their 
Impact on Cross-Cultural Tourist-Host Interaction. Journal of Business Research, 42, 175-187. http://dx.doi.org/10.1016/S0148-2963(97)00107-0

Reisinger, Y. (2009). Cross-Cultural Differences in Tourist Behavior. Handbook of Tourist Behavior, Theory \& Practice. Routledge, New York-London: Taylor \& Francis Group.

Ricks, D. A., Toyne, B., \& Martinez, Z. (1990). Recent Developments in International Management Research. Journal of Management, 16(2), 219-254. http://dx.doi.org/10.1177/014920639001600202

Schifman, L. K. (2007). Consumer Bahavior (7th ed.).

Sekaran. (1983). Methodological and Theorical Issues and Advancements in Cross Cultural Research. Journal International Business Studies, 14, 61-73. http://dx.doi.org/10.1057/palgrave.jibs.8490519

Selma, L., \& Uysal. (2012). Cross-Cultural Differences in Purchase Decision- Making Criteria. International Journal of Culture, Tourism and Hospitality.

Smith, P., Dugan, S., \& Trompenaars, F. (1996). National Culture and the values of Organizational Employees- a Dimensional Analysis across 43 Nations. Journal Cross-Culture Psychology. http://dx.doi.org/10.1177/0022022196272006

Soares, F. S. (2007). Hofstede's Dimensions of Culture in International Marketing Studies. Journal of Business Research, 60, 277-284. http://dx.doi.org/10.1016/j.jbusres.2006.10.018

Soares. (2004). The Influence of Culture on Consumers: Exploratory and Risk Taking Behavior. University of Minho.

Steel, P., \& Taras, V. (2010). Culture as a consequences: A Multi Level Multivariate, meta Analysis of The Effect Individual and Country Characteristics, on Work-Related Cultural Values. Journal of International Management. http://dx.doi.org/10.1016/j.intman.2010.06.002

Triandis. (2001). Individualism - Collectivism and Personality. Journal of Personality, 69(6), 907-924. http://dx.doi.org/10.1111/1467-6494.696169

Walls, A. R., Youcheng, W. (2011). Destination Marketing and Management Theories and Applications. CAB.

Woodside, A. G. (2008). Culture's Consequences on Experiencing International Tourism Services and Products; Quantitattive and Qualitative Fuzzy-set Testing of an Integrative of National Culture Applied to The Consumption behaviours of Asian, European and North American Consumers. Tourism Management.

Woodside, A. G., Shih-Yun, H., \& Marshall, R. (2011). General theory of cultures' consequences on international tourism behavior. Journal of Business Research, 64. http://dx.doi.org/10.1016/j.jbusres.2010.10.008

Yoo, B., \& Donthu, N. (1998). Validating Hofstede's Five Dimensional Measure of Culture at the Individual Level. American Marketing Association, Conference Proceedings, ABI/INFORM.

Yoo, B., \& Donthu, N. (2002). The Effects of Marketing Education and Individual Cultural Values on Marketing Ethics of Students. Journal Marketing Education, ABI/INFORM. http://dx.doi.org/10.1177/0273475302242002

Yoo, D., \& dan Lenartowicz. (2011). Measuring Hofstede's Five dimensions of Cultural Values at the Individual Level: development and Validation of CVSCALE. Journal of International Consumer Marketing, 23, 3-4.

Yuksel, K., \& Yuksel. (2006). Cross-National Analysis of Hotel Customers' Attitude Toward Complaining and Their Complaining Behaviours, Journal Tourism Management, 27.

\section{Copyrights}

Copyright for this article is retained by the author(s), with first publication rights granted to the journal.

This is an open-access article distributed under the terms and conditions of the Creative Commons Attribution license (http://creativecommons.org/licenses/by/3.0/). 